\title{
Linguistic Landscape and Space: A Multimodal Analysis of Linguistic landscape in Robot Open Space
}

\author{
Song Chen \\ School of English Language, Literature and Culture, Beijing International Studies University, Beijing 100024, China \\ E-mail: chensong1219@163.com
}

Received: 22-05-2016

Published: 01-11-2016
Accepted: 03-08-2016

doi:10.7575/aiac.ijalel.v.5n.6p.90
Advance Access Published: September 2016

URL: http://dx.doi.org/10.7575/aiac.ijalel.v.5n.6p.90

\begin{abstract}
The paper examines the linguistic landscape in an indoor public place, Robot Open Space in Zhongguancun Dream Laboratory, which is a building housing a handful of innovative entrepreneurial enterprises. The subject of analysis in this present paper is the impact of different spaces on the features of linguistic landscape. Each of the three major subspaces in the company Robot Open Space has different functions and the linguistic landscape with its different features varies accordingly. This present study has the following contributions. First, the shift of analytical attention from the outdoor linguistic landscape to the indoor linguistic landscape provides a new angle for LL analysis and further expands the scenery of linguistic landscape. Then, the newly establish analytical framework, the "multimodal model for linguistic landscape analysis" enrich the current theoretical models that is quite rare. Last, the qualitative analysis of the linguistic landscapes in different spaces shed light on the correlation between space and linguistic landscape, indicating that space is an integral factor to be considered when it comes to LL analysis.
\end{abstract}

Keywords: linguistic landscape; multimodal model; qualitative analysis; space

\section{Introduction}

While related studies on language in public spaces began much earlier (Rosenbaum, 1977; Spolky \& Copper, 1991; Calvet, 1990, 1994), the term "Linguistic Landscape" was first used by Landry and Bourhis in their seminal work entitled "Linguistic landscape and ethnolinguistic vitality: An empirical study" published in 1997. Ever since then, language in the public spaces as a new trend of study has drawn broad attention from researchers and scholars across the globe and in particular, linguists began to deal with this quiet new area from a linguistic perspective. According to Shohamy and Gorter (2009:1), "It is the attention to the language in the environment, words and images displayed and exposed in public spaces, that is the center of attention in this rapidly growing area referred to as linguistic landscape (LL)". With nearly two decades of development, research on this topic has proven very fruitful and diversified in foreign countries, with different scholars employing different theoretical approaches and perspectives in an attempt to interpret and understand languages in places and spaces in a deeper way. In the meanwhile, the large quantities of research conducted by linguistics further expand the boundary or, to use Shohamy and Gorter's words, the scenery of linguistic landscape.

Delighted we may be with the achievements we have obtained so far internationally, many problems with this topic emerge at the same time. For instance, we lack a unified definition of LL that is by and large accepted by all related researchers. The theoretical frameworks established in this field are relatively rare and immature, which poses a problem to many researchers when dealing with the LL studies. Another problem concerning the LL studies is that most of the researches conducted centers predominantly around the bilingual (or multilingual) aspect of LLs, discussing the presence or absence of particular language codes in public spaces. This preference to bilingualism in LL research leaves many other rich and interesting aspects untouched. In China, we are frustrated to realize that very few scholars are presently working on this topic with works and literatures from distinguished academics on this topic hard to find. Most academic studies conducted by Chinese scholars in this field are more often than not literature reviews, introducing and elaborating on the works, theoretical frameworks and research findings from foreign academics. True, the related research field, namely public sign research has attracted a host of scholars in China and a lot of works and academic papers have been published in the past decades. However, experts in this field mainly study public signs or in Chinese gongshiyu from the perspective of translation and focus on Chinese-English translation and the problems of translations of these public signs, which belongs to the category of translation ( $\mathrm{Li}, 2015: 5)$. It should be noted that this approach to signs study is far from enough considering the many definitions from many now eminent LL experts that indicates the scenery of linguistic landscape is much broader.

From the above elaboration, it is evident that linguistic landscape study in China is still at the initial stage, which means that much more can be done with this new area and new trend in China. The present study is an attempt to explore the correlation between linguistic landscape and public spaces. What distinguishes the present study is that in this paper, the analytical attention is turned towards the indoor public spaces, namely the indoor linguistic landscape as compared with 
the previous studies, which take outdoor LLs as research targets. Another point that is worth noticing is that a new analytical theoretical model is put forward to fill the gap of theories in the linguistic landscape research. The model, which I call "multimodal model for linguistic landscape" takes into consideration of the multimodal aspects of the linguistic landscape in present days. Our research efforts lead to three findings. First, the linguistic landscapes in the sales-experience space are more often than not advertisements and serves as a persuasive function. Second, the instructional area finds linguistic landscapes that tend to be instructional. Third, the large graffito put on the office wall signals that innovative ideas do matter for employees.

\section{Perspectives and Methodology}

\subsection{Perspectives}

As Shohamy and Waksman (2009: 314) have noted, "the creation of meaning of the LL texts as displayed in the public space, in its new and changing boundaries, is manifested within a variety of information design modes". The analysis of LL that solely takes into account linguistic aspect or the "mono modal" perspective can result in distortion and partial understanding of the phenomenon (Shohamy \& Waksman, 2009: 316). Apparently, in modern society, different meaning-making modalities find their way to the linguistic landscape. LL items in cities, particularly in metropolitan cities are more often than not diversified and multimodal communications. That said, two perspectives will be employed in this research. One is Kress and van Leeuwen's visual grammar, which is an excellent multimodal theoretical framework, and the other is Halliday's process type theory and speech function theory in the SFG framework.

\subsubsection{Visual grammar \& systemic-functional grammar}

Kress and van Leeuwen, drawing heavily on the important systemic-functional framework from M.A.K. Halliday, propose their own theoretical framework for visual communication interpretation, which has provided an excellent analyzing framework for visual communication and make great contribution to the development of multimodal discourse analysis (Xu \& Qu, 2009:3). As Kress and Leeuwen have pointed out, visual communication has resources for representation, interaction and composition, which is analogous to the three metafunctions: ideational, interpersonal and textual in Hallidayan systemic-functional grammar. Representational meaning can be classified into two subtypes, namely narrative representation and conceptual representation (only narrative representation will be used in the study). "Narrative patterns serve to present unfolding actions and events, processes of change, transltory spatial arrangement" (Kress \& Leeuwen, 2006:59). Representation of the narrative type consists of six processes, namely, Action processes, Reactional processes, Speech processes, Mental processes and Conversion processes. In short, "image can represent the world 'narratively' - that is, in terms of 'doing' and 'happening'” (Kress \& Leeuwen, 2006:73). Interaction meaning refers to the "interaction between the producer and the viewer of the image" (Kress \& Leeuwen, 2006:114). As Kress and Leeuwen put it, images and other kinds of visual involve two kinds of participants, represented participants and interactive participants. Interaction is composed of three elements: Contact, Social distance and Attitude. In the Contact element, two types of images are identified: Demand and Offer. Social distance can be specifically sub-classified into three types: Intimate, Social and Impersonal. With respect to Attitude, Subjectivity and Objectivity are two subtypes. The third major meaning is the meaning of composition. According to Kress and Leeuwen (2006:176), "there is a third element: the composition of the whole, the way in which the representational and interactive elements are made to relate to each other, the way they are integrated into meaningful whole". The compositional meaning of visuals is discussed in terms of three aspects: Information value, Salience and Framing (only Information value will be used in this study). In the dimension of Information value, the information values of Left and Right, Top and Bottom and Center and Margin are discussed.

Another perspective is Halliday's ideational metafunction and interpersonal metafunction. The ideational function of language is realized by the transitivity system. "The transitivity system construes the world of experience into manageable set of Process Types" (Halliday, 2014:170). There are altogether six types of process, i.e. material process, mental process, relational process, behavioral process, verbal process and existential process. Concerning the interpersonal function, we can generally identify four speech functions according to the commodity exchanged, namely offer, command, question and question and the modality system.

\subsubsection{The multimodal model for linguistic landscape study}

In a bid to better combine the two perspectives to serve the need of studying linguistic landscape, we are not just satisfied to do a one plus one job. Rather, we endeavor to pick out some of the most important aspects of both theories as we seek to design a more appropriate framework that fits the interesting and intriguing fields of study. Considering the nature of linguistic landscape, we pick out the process type and the speech function theories in SFG framework as well as narrative process and image act in the visual grammar. In addition, the spatial design aspect, which discovers the arrangement of visual and language and the related meaning conveyed, is also employed. These three major aspects, pertinent to the present study, contribute to establishing a new analytical model for linguistic landscape research, which I call multimodal model for linguistic landscape study. The multimodal framework is show in figure 2.1. As figure 2.1 has made very clear, in this theoretical model, two elements, namely the linguistic design and the visual design constitute two key modalities. Another modality, the spatial design relates linguistic design and visual design and excavates the interaction between the two major modalities. The three design or three meaning-making modalities constitute the whole linguistic landscape that is a multimodal communication or multimodal design. 


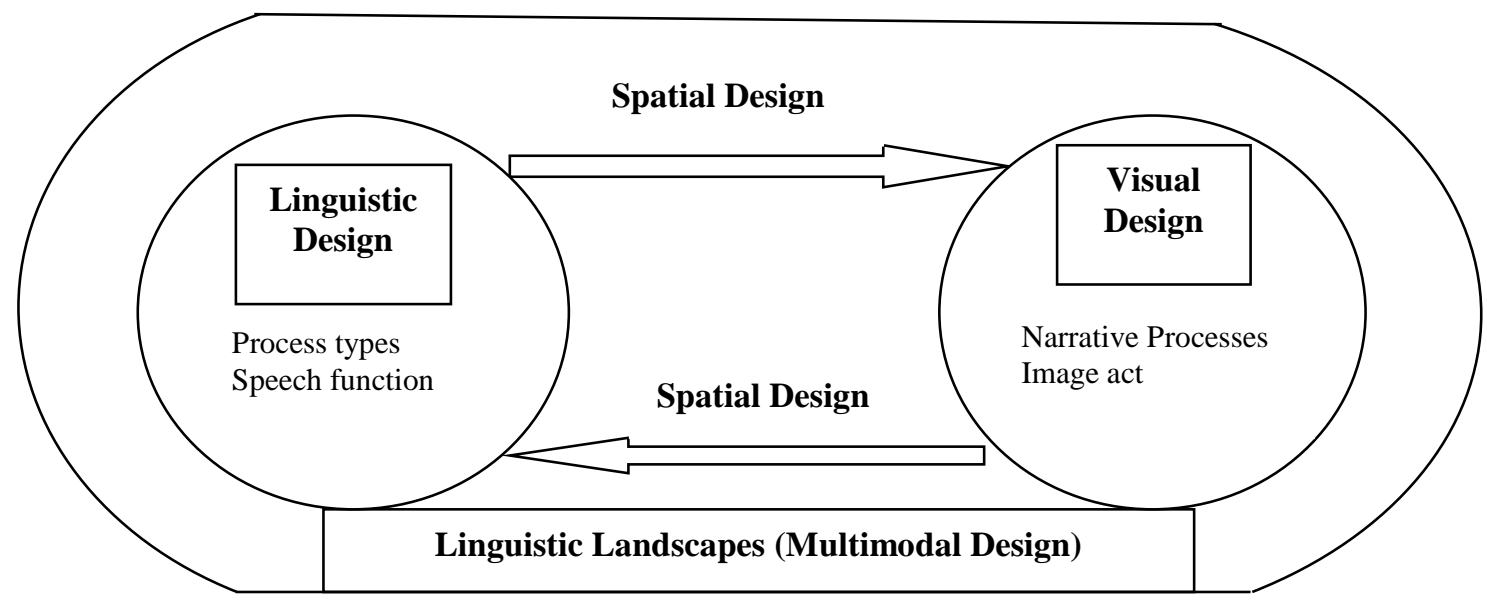

Figure 2.1 The multimodal model for linguistic landscape study

\subsection{Methodology}

\subsubsection{Research method}

In the present study, both quantitative and qualitative methods will be used. With regard to the qualitative analysis, we will focus on three dimensions, the linguistic design, the visual design and the spatial design. The analysis is aimed at discovering the interrelationship between linguistic landscape and space. As to the quantitative analysis, we will do some statistical analysis on the language displayed on the LL items from the perspective of process types to uncover the general regulations underlying the linguistic forms.

\subsubsection{Data collection}

The data collected for the present study is a result of a personal experience and observation in a company in Zhongguancun Dream Laboratory. Zhongguancun, always dubbed as the Silicon Valley in China, is a science \& technology innovation center with global influence. It is also the innovative entrepreneurial base for both domestic and overseas talents. Zhongguancun Dream Laboratory, which is situated in No1, Haidian Street, is one of the most important buildings in Zhongguancun and therefore is called the "Building N0.1 of Zhongguancun". The building currently houses 11-odd science \& technology companies in addition to some other administrative offices. The company, Robot Open Space on the second floor is selected as the research places. It should be noted that the company is not a company in the normal sense, but a laboratory-like public space designed for selling robot products and offering robotics classes to students. A huge collection of visitors and students will visit this company on a daily basis. All the data are collected by taking photos via digital camera.

\section{A qualitative and quantitative analysis of the linguistic landscape in the Robot Open Space}

According to the introduction from the people in charge, Robot Open Space consists of three main spaces, namely sales-experience area, instructional activity area and office area. The sales-experience area is a space where customers can experience in person different kinds of robots and get some knowledge of robotics and the price of each robot provided via the help of salesperson. Instructional activity area provides a space to get robotics learning students involved in the process of making robots themselves under the guidance of teachers and practice their robot-related theories. Another space, the office area, where employees work and discuss also constitutes an important part in the whole company. The careful observation of the linguistic landscape in these different areas reveals that there is a correlation between space and linguistic landscape. In other words, different linguistic landscape features reflect different space functions.

\subsection{Situating linguistic landscape in the sales-experience area}

The sales-experience area, a large space in the company, is a place where customers (mostly parents together with their kids) can experience in person the robots provided on the one hand and asking for process and other robot-related information from the salesperson there on the other, hence the name sales-experience area. The general layout of this area is recoded via digital camera and is demonstrated in figure 3.1 .

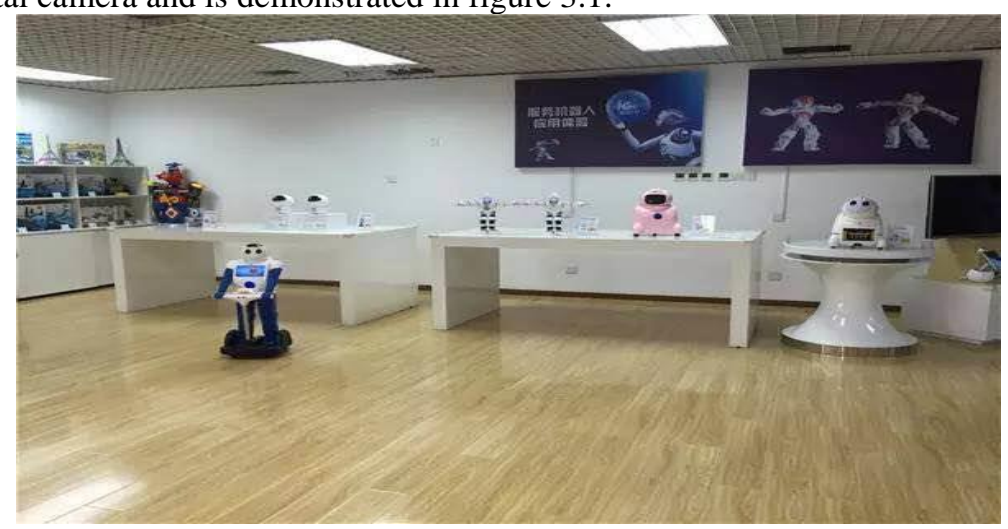

Figure 3.1 The layout of the sales-experience area 
As can be seen in figure 3.1, the whole space is made up of two different functional sub-areas: display areas and a spacious interactive area for customers to interact with different robots. In the sales-experience area, the linguistic landscapes are mainly displayed via one major floor-standing electronic screen and two TV sets hung on the wall. As one of the function or purpose of this space is to sell robot products, the linguistic landscapes that are visible in this area are more often than not advertisements. It is not difficult to predict that the linguistic landscapes here are mostly multimodal, which are capable of conveying rich meanings. For instance:

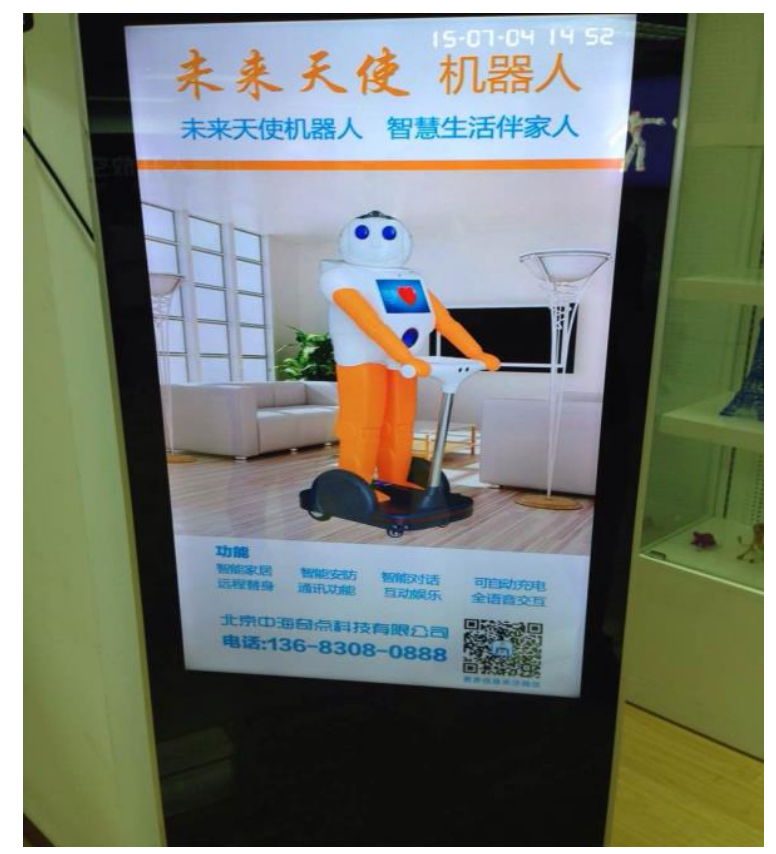

Figure 3.2 The linguistic landscape in the sales-experience area

This linguistic landscape, or more specifically the advertising billboard, is displayed in a very important place at the corner that is easy to spot for customers. Apparently, there are linguistic design, visual design and spatial design on the item, and the interaction between different modalities. As such, this is a typical multimodal communication.

\subsubsection{Linguistic design}

The language part on this panel is quite simple but meaningful. First, the language displayed on the top of the panel:

\section{Chinese: 未来天使机器人 未来天使机器人 智慧生活伴家人}

English translation: Future Angel Robot

Future Angel Robot Smart life will accompany your family

At first glance, the simple, slogan-like words have nothing special. But a careful analysis from the perspective of process types and speech function unveils more underlying meanings. In the first place, “未来天使机器人” (Future Angel Robot) is the name of the robot displayed on the screen. On the very top of the advertisement, the name is given accompanied with the advertising words "Future angel robot / Smart life will accompany your family". It seems that these are two separate units, but if we go a step further to explore the logic behind the two parts, it can be revealed that there is a connection between the two. "Future Angel Robot" and "Smart life will accompany your family" are two linguistic units combined as a meaningful clause. If the underlying logic is reflected linguistically, we can get the clause "With Future Angel Robot, smart life will accompany your family". In terms of the process types in Halliday's SFG framework, “未来天使机器人 智慧生活伴家人” (With Future Angel Robot, smart life will accompany your family) is a material process, with the action verb being “伴” or accompany in English. To present the clause structure schematically, we will get the following configuration:

\begin{tabular}{llll}
\hline Circumstance & Actor & Process: material & Goal \\
\hline 未来天使机器人 Future Angel Robot ) & 智慧生活 ( Smart life ) & 伴 ( accompany ) & 家人(your family ) \\
\hline
\end{tabular}

Figure 3.3 The configuration of the material clause

Apart from the perspective of process types, the advertising words also realize the speech function although they are not presented as a speaker-listener pattern. It is evident that the 'commodity exchanged' in this case is information and the 'speech role' of the words is giving. Taken together, these two variables define the speech function of an 'offer' type. That being said, the speech function of the words on the top is an offer, giving information of the Future Angel Robot to the viewer via a words-viewer pattern. 


\subsubsection{Visual design}

It is quite noticeable that the visual design takes up a large part on the LL item. At the center of the advertisement, we see a robot is riding an electronic vehicle at the sitting room of a family. The robot, whose name is Future Angle Robot, is looking at the viewer squarely. In the narrative representation system developed by Kress and van Leeuwen, if the represented participant in the visual communication forms an eyeline or a direction of the glance, it is identified as a Reactional process. The configuration of the narrative process of the visual can be shown as follows:

\begin{tabular}{lcc}
\hline Reactor & Vector : Reactional & Phenomenon \\
\hline & Figure 3.4 The configuration of Reactional process
\end{tabular}

It is worth pointing out that in this visual, the phenomenon is absent, which means it is not a complete "Reactor + Vector + Phenomenon" pattern, but a "Reactor + Vector" or a non-transactional type. The represented robot is not looking at other represented participants in the image, but looking directly at the viewer, who is not the represented participant but the interactive participant. Therefore, it can be interpreted that it is left to the viewers to imagine what the robot is thinking about or aiming at. As is mentioned, the represented participant, the robot in the visual image looks at the viewer, which means the vector connect the robot with the viewer. It is recognized as a 'demand' according to Kress and van Leeuwen's visual grammar, an image act that seems to do something to the viewer or demand something from the viewer. In this particular image, the robot's action, who is looking at the viewer directly, can be understood as wanting the viewer's attention and then persuade the consumers to buy the products.

3.1.3 Spatial design

Having discussed both the linguistic dimension and the visual dimension, we come to the analysis of the visual design. As Kress and van Leeuwen (2006: 176) put it, "the placement of the elements (of the elements and of the syntagms that connect them to each other and to the viewer) endows them with specific information values relative to each other". The spatial design or the composition meaning proposed by Kress and van Leeuwen is composed of three interrelated systems, namely information value, salience and framing. As can be seen in figure 2, the layout of the whole linguistic landscape item forms a vertical triptych, a term used by Kress and van Leeuwen to describe an Ideal - Mediator - Real model that can be schematically illustrated in figure 5 .

\begin{tabular}{l}
\hline Ideal \\
\hline Mediator \\
\hline Real
\end{tabular}

Figure 3.5 The spatial pattern of the whole linguistic landscape

Therefore, it is not difficult to conclude that the words at the top represent the Ideal part in the whole design whereas the language at the bottom constitutes the Real part. Specifically speaking, the slogan-like advertising words that occupy the upper part is ideal. It is quite understandable since advertising slogans always present ideal description to attract consumers. However, the words at the bottom that list the functions of Future Angel Robot represent the Real part, meaning all the listed functions can be realized by the robot product and by and large real. It can be reviewed that the LL designer makes full use of the central space to draw viewer's attention to the robot represented. The central space where the image of the robot occupies also serves as a mediator between two linguistic parts at the top and bottom to enable a whole linguistic landscape.

In summary, the linguistic landscape discussed above is a reflection of the spatial property of the sales-experience area. On the one hand, the function or major purpose of this space has a profound influence on the design of linguistic landscape and on the other hand the linguistic landscape also defines the space as a persuasive place where customers are in the position to be persuaded to buy robot products.

\subsection{Situating linguistic landscape in the instructional activity area}

Another major space in this company is the instructional activity area, where students take robotics classes. This area is segmented into three individual small classrooms as is shown in figure 3.6:

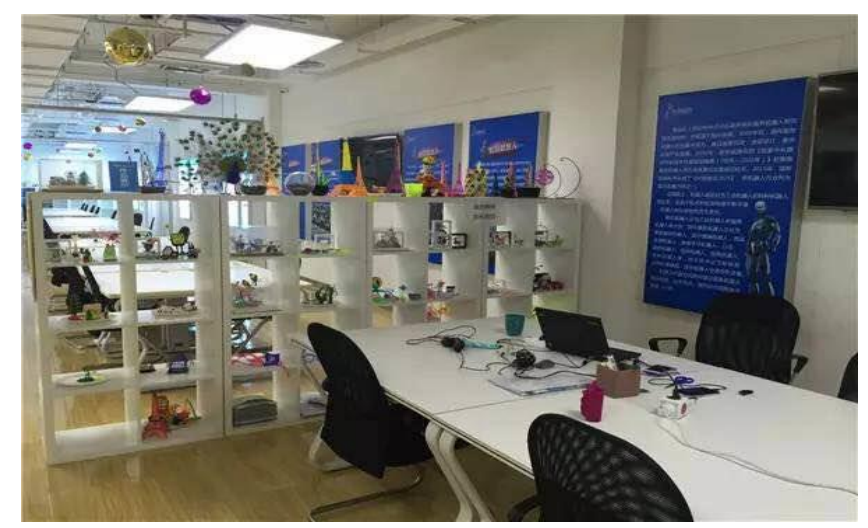

Figure 3.6 The layout of the instructional activity area 
In this space, there are altogether 14 electronic screens hung on the wall. The major linguistic landscapes in this area are displayed on these screens with the purpose of providing basic instructional information on robotics for students and their parents alike and other customers. The information includes the brief introduction to robots in general and the different types of robots, their functions and development trend in particular. It is quite obvious that language plays a vital role on the linguistic landscapes seen in this space. The language, which is accompanied by and interacted with various images, displays unique features and therefore deserves special analysis. We first do some statistical analysis on the language designs on the 14 collected linguistic landscapes from the perspective of process types in a bid to discover the distribution of different process clauses. Then, some of the clauses will be picked out for qualitative analysis.

\subsubsection{Linguistic design}

The language appears on all the data collected in this space are cut into clauses and analyzed from the perspective process types. In the meantime, statistical analysis on the data is made to provide an overview of the distribution of different process clauses on the linguistic landscape displayed here. The following are the statistical results:

Table 3.1 The distribution of different process types in the linguistic designs

\begin{tabular}{lll}
\hline Process types & Frequency & Percentage \\
\hline Material process & 61 & $52.1 \%$ \\
\hline Mental process & 2 & $1.7 \%$ \\
\hline Relational process & 51 & $43.6 \%$ \\
\hline Verbal process & 1 & $0.9 \%$ \\
\hline Behavioral process & 0 & $0 \%$ \\
\hline Existential process & 2 & $1.7 \%$ \\
\hline
\end{tabular}

From the above table, it can be seen clearly that clauses of the material type top the list, followed by the relational process clauses. Among other 4 types, there are only 2 mental process clauses, 2 existential clauses, 1 verbal process clause and there is no behavioral process clause. That is to say material process clauses and relational process clauses dominate in the linguistic designs on the 14 linguistic landscapes. The following two figures are examples of linguistic landscape items in this area.

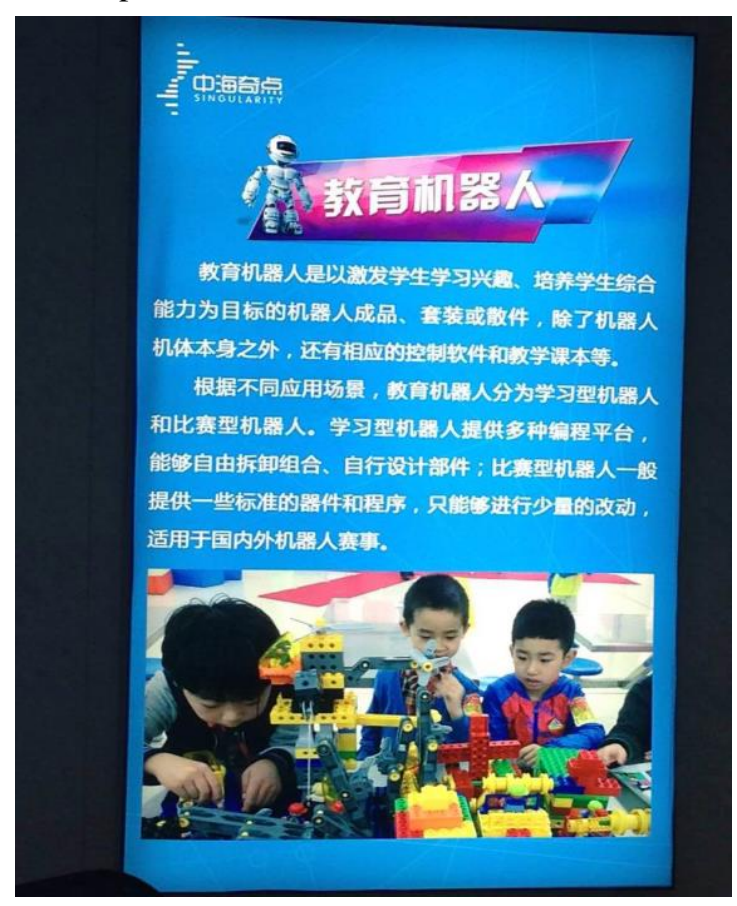

Figure 3.7 Linguistic landscape in Instructional area

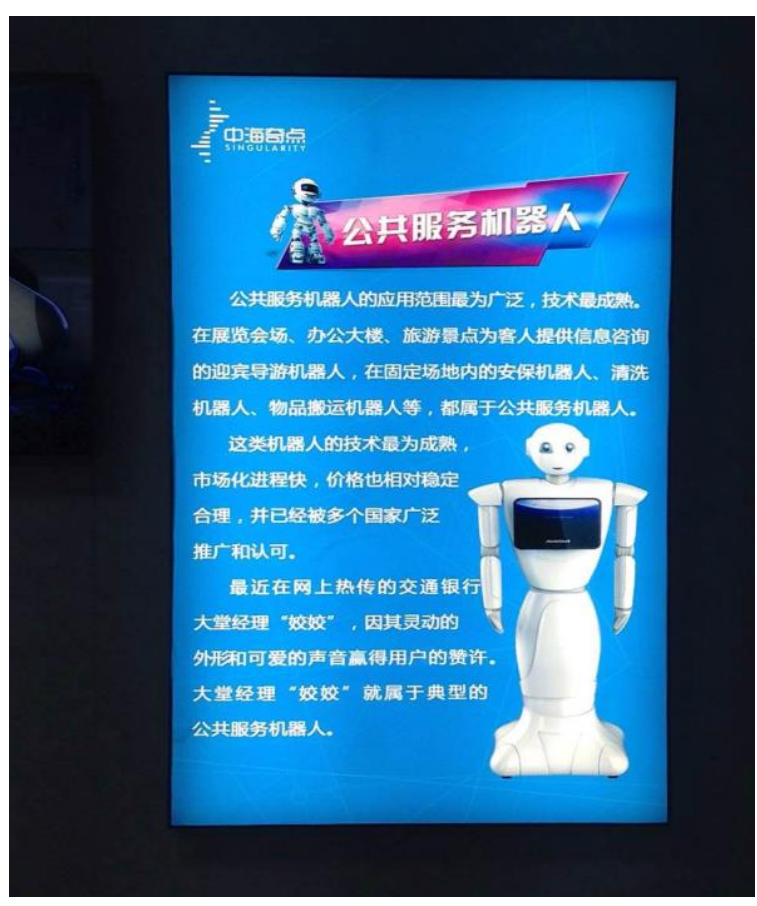

Figure 3.8 Linguistic landscape in Instructional area

As is demonstrated in figure 3.7, the language part on this particular linguistic landscape occupies a large proportion of the whole item. In terms of process types, the verbal part is made up of 8 clauses altogether. Among them, 3 are relational process clauses and 5 are material process clauses. For instance:

(1)Chinese: 教育机器人是以激发学生学习兴趣、培养学生综合能力为目标的机器人成品、套装或散件...

English translation: Educational robots are interest-oriented and comprehensive capability building robots, robotic suits and robot parts...

(2) Chinese: 学习型机器人提供多种编程平台，能够自由拆卸组合、自行设计部件... 
English translation: Education robots provide multiple programming platforms and enable disassembling \& assembling and designing parts.....

Example (1) is a typical relational process clause with a figure: Be-er1 + Process: Relational + Be-er2. Be-er1 is taken up by “教育机器人” (educational robots) and the Process is represented by the “是” (are) while the rest of the clause forms the Be-er2. Semantics-wise, the clause introduces what exactly an education robot is. As is shown in table1, relational processes constitute a huge part in linguistic designs in all the data collected at the instructional area. The reason behind this predomination is that the relational process clauses are excellent structures to inform the students of the knowledge of robotics. In example (2), two clauses are combined to form a clause complex. The material clause figure is represented as Actor + Process: material + Goal, with process represented by verb or verbal group. It can be discovered that in all the identified material clauses, a large proportion of the verbs are employed to describe what each kind of robot can do for human being or for robotics education. It is quite apparent that in example (2) the verb or verbal groups “提供"(provide), “拆卸组合、自行设计"(disassemble \& assemble and design) all describe what the educational robots can offer in terms of programming and designing parts.

\subsubsection{Visual design}

While the displayed language, or specifically the instructional language plays a significant role on the LL items in the instructional space, visuals also find their way there. Each of the 14 LL items also shows different visual designs accompanying the language part in one form or another, which is demonstrated in figure 7 and figure 8. In figure 7, for example, the visual design, in which three children are involved in the process of designing parts of robots, can be regarded as conveying different representational meanings. A careful observation unveils that the three children (the represented participants) represent two processes: action process and reactional process. The boy on the very left side is doing something on the robots in front of him with some instrument. His two hands form two vectors that is directed to the robot on the table, therefore the boy is the Actor and the robot is the Goal, hence the configuration Actor + Action process + Goal. The two boys on the right, however, are noting doing something, but rather looking at the robot. There eyelines form two vectors respectively and constitute two reactional processes with the two boys as the Reacters and the robot as the Phenomenon. With respect to the interactive meaning, since the image in the linguistic landscape does not contain participants looking directly at the viewer, it serves as the image act of the 'offer' type. The visual design is primarily used to provide information rather than asking for something from the viewer.

3.2.3 Spatial design

The special layouts of the linguistic landscapes collected in the instructional area have many in common. That is on most LL items, the visual image is placed at the bottom of the whole linguistic landscape. Some items show the image placed at the bottom right corner. For example, in figure 7, the image is displayed at the bottom of the whole linguistic landscape, which forms the top - bottom visual configuration. In line with the information value system proposed by Kress and van Leeuwen $(2006,177)$, the top - bottom layout signifies an Ideal - Real paradigm. That is to say, the upper part, or specifically the linguistic part of the LL shown in figure 7 can be seen as the Ideal part, meaning the information introducing the robots for educational purposes is something ideal or something we hope to achieve while the bottom part, or the visual design, constitutes the Real part, demonstrating what people do with educational robots in reality.

Therefore, it is reasonable to argue that the linguistic landscapes here in the instructional activity area are instructional and informative in nature and the visuals are designed mostly for showcasing each type of robots as images are vivid way of illustrating. The reason behind this is that the major function of the instructional area is to give classes on robotics and this space property impact the whole design of linguistic landscapes. The features and designs of the linguistic landscape in turn reflect the nature of the space.

3.3 Situating linguistic landscape in the office area

The third major part of the company is the office area where employees work. It is worth pointing out that most of the employees are teachers in robotics. In this space, a large graffito (figure 9) that occupies a whole wall presents itself in front of the employees and consumers.

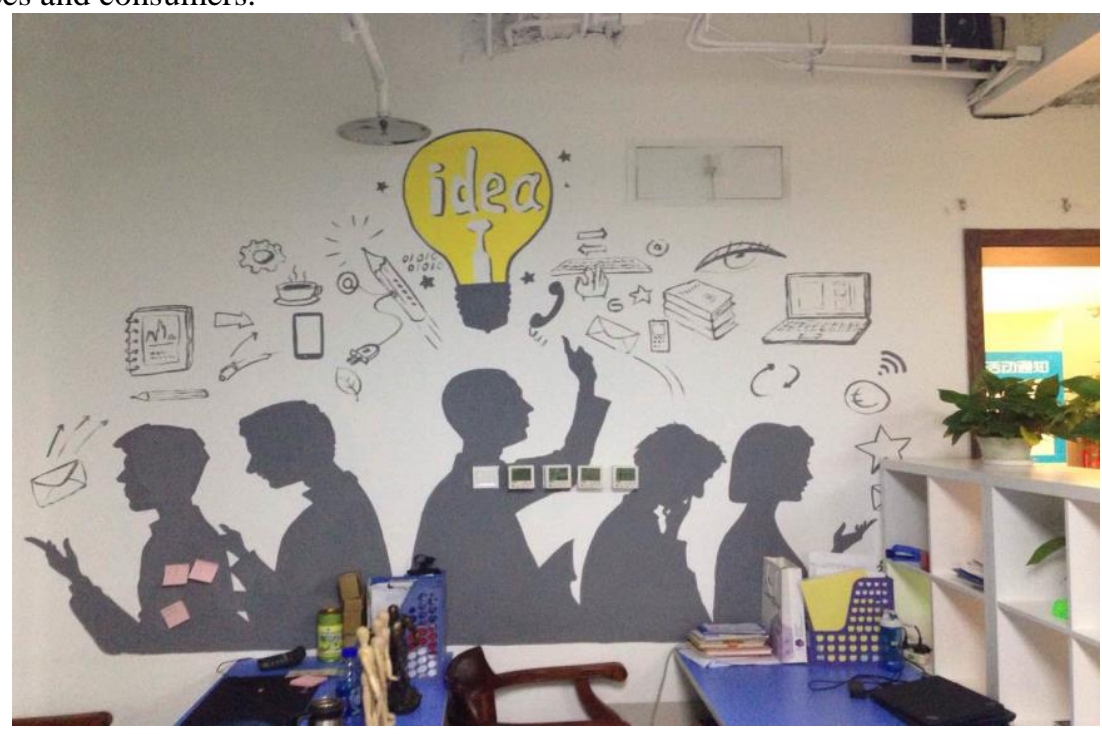

Figure 3.9 The linguistic landscape in the office area 


\subsubsection{Linguistic design}

As can be told from figure 3.9, the linguistic part in the linguistic landscape is quite simple. The visible language includes the word "idea" and a string of codes " 0101001010 ". Since both "idea" and the string of codes do not express the material world in terms of a Actor + Process + Goal paradigm, the process type discussion on this item will be skipped over. As to the speech function of the language here, it is the offer of information, and the single word "idea" which finds itself in the light bulb obviously signals the importance of innovative ideas for employees working here. The binary codes, which are often used in electronic information engineering and computer technology, here imply that most of the work being done here has close connection with information technology or digital technology.

\subsubsection{Visual design}

The visual design of this graffito presents rich meaning that is worth careful analysis. First of all, the major visual elements on the LL item are five human figures. Among the five, the one in the middle forms the most salient figure. Judging from the design of the figure in the middle, it can be clearly concluded that he (the figure) has just come up with a good idea. The idea is represented in the image of a light bulb. The other four figures, some are absorbed in musing over something and some are looking ahead and holding out their hands. Above them are several different images such as notebooks, smartphones, computers, books, keyboard, envelops, the icon of WIFI and others. These elements are closely bound up with information technology and computer technology. It is obvious that the visual presents a series of action processes and it is also an offer in the sense that there is no direct eyeline interaction between the represented and interactive participants.

\subsubsection{Spatial design}

Generally, the spatial layout of this graffito can be seen as presenting the Ideal - Real structure. According to Kress and van Leeuwen (2006: 186), "what has been placed on the top is presented as the Ideal and what has been placed at the bottom is put forward as the Real". Largely, the upper section is designed to make some emotive appeal to the viewer and aims to represent what might be whereas the lower section is prone to be more practical and demonstrates what is. As can be seen from figure 9, the whole visual composition turns out to be an Ideal - Real model with the upper elements in the realm of the ideal and the lower elements in the realm of the real. On the top of the graffito, the light bulb, the most salient element occupies the center of the upper part and other represented elements such as smartphones, computers, books, keyboards surround the central element. It should be pointed out that even though the word "idea" is simply a word, it occupies the central place at the upper part, which is an indication that idea is quite important for employees here in the office area. The whole upper part constitutes the ideal realm of the whole composition, which seems to be saying that innovative idea is something ideal and all the employees will pursue. Moving to the lower part, the real part, we can see that five human figures, some of which is musing over something while others are holding out their hands and seeing ahead. The lower part obviously takes up the real part of the linguistic landscape. The meaning it conveys seems to be that in order to come up with innovative ideas, employees need to work hard and think hard.

\section{Conclusion}

As one of the existence forms of matter, space is the environment upon which human beings rely (Wen \& Kang 2004: 81). People live in and interact with spaces and therefore will use language as a means to represent the space. This present paper is an attempt to explore the untapped research field of linguistic landscape studies and contributes to the further expansion of the scenery of linguistic landscape. Taking a multimodal perspective, this study first establishes an analytical model for linguistic landscape studies. Then, targeting the three different areas in a company, we probe into the interrelationship and interaction between linguistic landscapes and spaces. In the first place, the linguistic landscape in the sales-experience makes full use of the visual design, which serves as a 'demand' image act and accompanied by the linguistic design, and defines the space as a sales-experience area that is persuasive in nature. Secondly, the linguistic landscapes in the instructional activity area are informative and instructional. In this space, the linguistic designs play a significant role in providing robotics information for learners and consumers. It is important to note that the statistical analysis on the language on all the LL items collected in this area unveils the predomination of the uses of material process clauses and relational process clauses, which reflects the instructional purposes of the language. Thirdly, the large graffito on the wall of the office area is an Ideal-Real layout in terms of spatial design and even though the language in this visual communication is simply the word "idea", its key role in enlightening the office employees can never be ignored considering its position in the Ideal realm. The visual design of the graffito, which is of equal importance, occupies the lower part, forming the Real. The whole LL design points to the innovative spirit in the office area.

The present study provides a look at the linguistic research from a multimodal perspective. On the one hand, the theoretical model established add to the inventory of theoretical frameworks for linguistic landscape studies that is quite rare. On the other hand the shift from outdoor linguistic landscape to the indoor linguistic landscape and the discussion of LL and spaces distinguishes the study from the previous ones and will definitely offer inspirations to researchers in this field. The linguistic landscape analysis helps to shed light on the properties of different areas and enable an in-depth understanding about the interrelation between linguistic landscape and spaces. Therefore, the study has both theoretical significance and pragmatic significance. 


\section{References}

Cenoz, J., \& Gorter, D. (2006). Linguistic landscape and minority languages. International Journal of Multilingualism, 3, 67-80.

Halliday, M. A. K. (2004). An Introduction to Functional Grammar. Edward Arnold Publishers.

Hu, Z. L. (2007). Multimodalization in Social Semiotics. Language Teaching and Linguistic Studies, 1, 1-10.

Kress, G., \& van Leeuwen, T. (2006). Reading Images: The Grammar of Visual Design. London: Routledge.

Li, L. S. (2015). A Review of International Linguistic Landscape Studies and Its Implications. Journal of Beijing International Studies University, 240(4), 1-7.

Li, Z. Z. (2003). Social Semiotic Approach to Multimodal Discourse. Foreign Languages Research, 81(5), 1-8.

Li, Z. Z., \& Lu, D. Y. (2012). Multimodal Semiotics: Theoretical foundation, method and development trend. Foreign Languages Research, 132 (2): 1-8.

Landry, R., \& Bourhis, R. (1997). Linguistic landscape and ethnolinguistic vitality: An empirical study. Journal of Language and Social Psychology, 16, 24-27.

Shohamy, E., \& Gorter, D. (2009). Linguistic Landscape: Expanding the Scenery. London: Routledge.

Shohamy, E., Ben-Rafael, E., \& Barni, M. (2010). Linguistic Landscape in the City. Britain: Multilingual Matters.

Scollon, R., \& Scollon, S. (2003). Discourse in Place: Language in the Material World. London: Routledge.

Shang, G. W., \& Zhao, S. H. (2014). Linguistic Landscape Studies: Perspectives, Theories and Approaches. Foreign Language Teaching and Research (bimonthly), 46(2), 214-223.

Shang, G. W., \& Zhao, S. H. (2014). Linguistic Landscape Studies: Analytical Dimensions and Theoretical Construction. Journal of Foreign Languages, 37(6), 81-89.

Xu, G. H., \& Qu. H. (2009). Multimodal Discourse Analysis - A New Perspective of the Information Era. Shandong Foreign Language Teaching Journal, 129 (2), 3-7.

Yu, W. Q., \& Wang, T. T., \& Sun, Y. N. (2016). A survey on the Multilingual Landscape of Foreign Resident Communities in International Metropolises -A Case Study of Wangjing, Beijing and Gubei, Shanghai. Applied Linguistics, 1, 36-44. 